\title{
The Determination of Predictive Construct of Physical Behavior Change on Osteoporosis Prevention Women Aged 30-50: A Trans-theoretical Method Study
}

\author{
Farideh Malekshahi ${ }^{1}$, Alireza Hidarnia ${ }^{1}$, Shamseddin Niknami ${ }^{1}$ \& Frakhondeh Aminshokravi $^{1}$ \\ ${ }^{1}$ Department of Health Education, Faculty of Medical Sciences, Tarbiat Modares University, Tehran, Iran \\ Correspondence: Alireza Hidarnia, Department of Health Education, Faculty of Medical Sciences, Tarbiat \\ Modares University, Tehran, Iran, Tel/Fax: 98-21-2384-2565. E-mail: Hidarnia@modares.ac.ir
}

Received: March 31, 2015 Accepted: June 17, 2015 Online Published: July 27, 2015

doi:10.5539/gjhs.v8n3p183 URL: http://dx.doi.org/10.5539/gjhs.v8n3p183

\begin{abstract}
Osteoporosis is a major public health priority in Iran and throughout the world. The prevention of osteoporosis has recently become the ultimate goal of many health professionals. Behavior change is one of the most powerful strategies to prevent osteoporosis. This study aimed to determine the predictive construct of physical preventive behavior of osteoporosis in women aged 30-50 in Khorramabad, west of Iran. This study included 269 women selected from all the health centers of Khorramabad city according to the inclusion criteria of the study and through random cluster and systematic sampling. The data gathering tools were valid and reliable questionnaires of demographic information, stages of change, decisional balance, self-efficacy, and physical activity. Data were analyzed using descriptive and inferential statistics. The mean of the subjects' age was $38.72 \pm 7.003$, and the mean of light weekly physical activity was $38.83 \pm 56.400$. The results showed that the construct of self-efficacy had the highest predictive power of the preventive behavior. The results also showed that self-efficacy among the constructs of the Trans-theoretical Model was the only predictive construct for osteoporosis prevention behavior. Therefore, the findings of this study can serve as a base for educational interventions in behavioral changes to prevent of osteoporosis by health authorities.
\end{abstract}

Keywords: osteoporosis, trans-theoretical model, self-efficacy, prevention, physical activity, women

\section{Introduction}

Osteoporosis is the most common type of metabolic bone disease in which bone mass reduces with age. This disease has been known as an important health priority in community public health, particularly in women (Hazavehei et al., 2007; Tussing \& Chapman-Novakofski, 2005). The disease remains asymptomatic until bone fracture, and therefore it is also referred to as "silent thief" (Chan et al., 2007). The prevalence of osteoporosis varies among countries and even within countries (Hazavehei et al., 2007). Previous studies have shown that the prevalence of osteoporosis in Iran is mostly at the age of 50 or over, $22.2 \%$ in females, and $11 \%$ in males (Adib \& Nauroy, 2011; Salehi et al., 2009). A fracture due to osteoporosis happens every 3 seconds, and a fracture in the spine occurs every 22 seconds worldwide (PDO, 2006). So that one out of two women over the age of 50 experiences vertebral fractures, and one out of three men over 50 experiences hip fractures in their lifetime, and both of these conditions lead to significant morbidity and mortality (PDO, 2006; Schwellnus et al., 2011). According to global statistics, Iran, like other countries, will have a considerable population of the elderly the next 50 years, so that $14 \%$ of the population (11 million people) are 50 or over and $3.6 \%$ (2.6 million people) 70 or over, and around $34 \%$ of the population (42 million people) will be 50 and over by 2050 (Adib \& Nauroy, 2011). The costs of the disease will be enormous (Khorsandi et al., 2011; Moayyeri et al., 2006) so that the medical cost of osteoporosis-related fractures has been more than 22 billion dollars in the USA (Blume \& Curtis, 2011). If effective preventive measures are not taken and consistently promoted, it is predicted that the cost of osteoporosis will rise to 200 billion dollars in the world before the year 2040 (Blume \& Curtis, 2011). Osteoporosis prevention and its subsequent fractures is the objective of many healthcare professionals (Tussing \& Chapman-Novakofski, 2005). According to researches, obtaining a high bone density and maintaining it during lifetime play a major role in preventing osteoporosis in old age (Heaney \& Weaver, 2003). Studies have shown that physical activity plays an important role in the prevention of osteoporosis (Lowe et al., 2011; Sharma et al., 2010; Khawaji et al, 2010; Khorsandi et al., 2011). Regular physical activity can have a positive effect on 
bone mass during lifetime (Alev \& Yurtkuran, 2003). Physical activity has obtained a special place in the context of medical science as a therapeutic method (DWS, 2005). Therefore, physical activity, particularly if it is accompanied by weight bearing, results in maintaining and even increasing bone mass through exerting mechanical pressure on bones (Maimoun et al., 2005; Habibzadeh et al., 2009; Ebrahim et al., 2010). Moreover, since behavior change is the basis and foundation of preventing many health-associated risks (Rollnick et al., 2007), so it has been recommended as an effective way to prevent osteoporosis (Karimzadeh Shirazi et al., 2007; Glanz et al., 2008). Experts believe that the efficacy of health education and behavior change programs depends largely on the use of models and theories of health education (Butler, 2001; Araban et al., 2013). The first step of each health education is to choose suitable model for health education (Glans et al., 2008). On the other hand, since the prevention of behavioral factors influencing osteoporosis requires individuals' behavioral change (Glanz et al., 2008; Araban et al., 2013), the models and theories of health education and health promotion can be effective in designing interventions in this field at different levels (level 1, level 2 or even level 3) of prevention (Parker et al., 2004; Araban et al., 2013). A health education model which can be used to change behavior at individual level is the Prochaska Trans-theoretical model (Prochaska et al., 1992; Prochaska \& Marcuse, 1994). The model has been used for a vast range of health behaviors since its introduction (Araban et al., 2013; Salehi et al., 2010; De Vet et al., 2007; Schüz et al., 2009; De Vet et al., 2008; Marcus et al, 1994; Prochaska \& DiClement, 1983; Lawrence et al, 2005), this method can predict the way and time of behavioral change (Sharma \& Romans, 2008).

The model has four constructs including "stages of change", "process of change", "self-efficacy", and "decisional balance" (Velicer et al., 2001) The construct of "stages of change" has been recognized as a comprehensive model of behavior change. This model focuses on an individual's preparation or effort to change and progress towards healthy behaviors. The importance of the model is for the reason that it shows the occurrence of change in the five stages (Parker et al., 2004) and suggests that people need different interventions at any stage (Figure 1). The first stage is "pre-contemplation" in which the individual does not speculate about behavior change within 6 months. Two groups of people fall into this stage: first, people who are unaware or have little information, these people are not aware of the consequences of behavior; second, those who have experienced change but have failed in the past, these people are resistant to change. The second stage is "contemplation" in which the individual thinks about behavior change in the future (within 6 months). People in this stage will weigh the benefits (pros) and the costs (cons) of behavior change and hence stay longer in this stage. The third stage is "preparation" in which the individual thinks about plans for behavior change in the near future and usually the next month. People in this stage have some plans for change and have taken actions. The next stage is "action" in which the individual has changed behavior during the last 6 months, and new behaviors can clearly be observed in this stage. The last stage is "maintenance" in which the individual has taken actions to maintain behavior change for a long time (6 months or more) (Glans et al., 2008). People in each stage require different interventions, and this categorization will enable us to intervene with regard to the stage which shows how a behavior changes in each of the stages. The processes of change include activities and strategies that will help the individual to progress in the change stages, and include two main types of cognitive processes (related to the individual's thoughts and feelings about unhealthy behavior) and behavioral processes (causing changes in unhealthy behavior). The application of these processes results in strengthening the individual in adopting new behavior and maintaining the behavior (Lee, 2004).

The third construct of the model is "decisional balance", which is defined as the benefits (pros) and costs (cons) of behavior change from the individual's view (Prochaska \& Velicer, 1997; Yalcinkaya-Alkar \& Karanci, 2007. According to this model, change occurs when the benefits are greater than the costs. This model is particularly important in the pre-contemplation and contemplation stages (Yasin et al., 2011; Prochaska et al., 2008), and the benefits and costs are similar to those in the health belief model (Prochaska \& Velicer, 1997).

The fourth construct of the model is "self-efficacy", which refers to the individual's perceived confidence in the ability to perform a certain behavior successfully. The construct has been adopted from Bandura's social learning theory and Shiffman's model of consistency and relapse (Bandura, 1982, 1997, 2006). This construct is unique to the relevant behavior and has a pivotal role in changing behavior and moving toward higher stages of change. It also has a direct linear correlation with the stages of change. In this regard, some strategies have been recommended to enhance self-efficacy such as breaking the behavior into small, simple, and practical stages, taking advantage of persuasion, reducing stress, and using believable role patterns (Sharma \& Romans, 2008). 


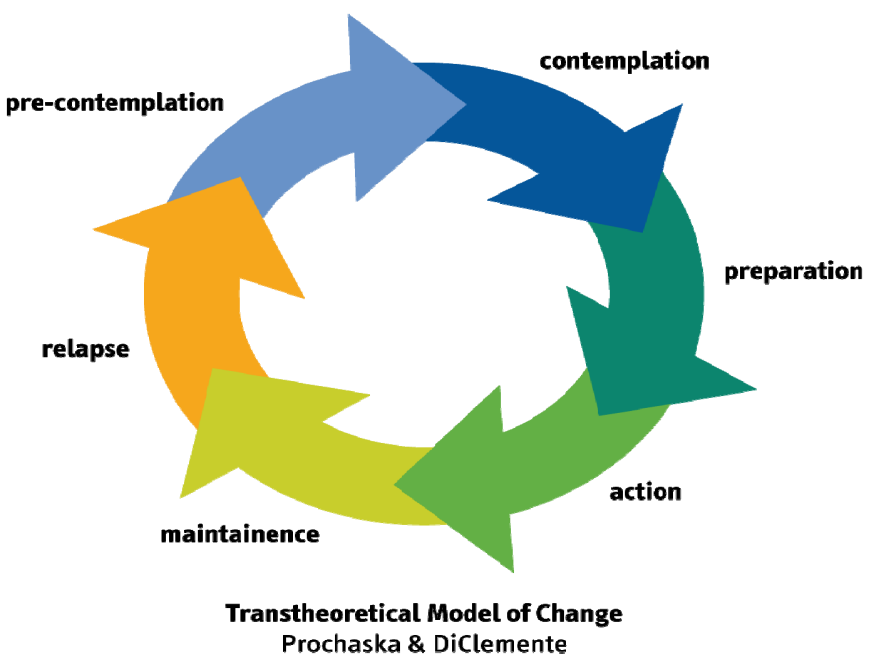

Figure 1. Stages of change in the TTM

This construct has a central role in changing behavior and entering the higher stages of behavioral change (Prochaska et al., 2008). Finally, the model usually interprets behavior change as an event, and evaluates overt behaviors in the end points.

In order to modify osteoporosis prevention behaviors such as regular physical activity that requires behavioral continuity unlike simpler and one-step behaviors, it is logical to apply those models which are sensitive to different stages and small steps of change (Araban et al., 2013). Therefore, the present study aimed to determine the predictors of behavior change in osteoporosis prevention in women aged 30-50 years in the city of Khorramabad (west of Iran). It is hoped that theory-based interventions are designed through identifying the factors influencing the behavior in order to take an important step in improving women's health.

\section{Materials and Methods}

This descriptive-inferential cross-sectional study included 269 women aged 30-50 years old referred to the health care centers of Khorramabad, west of Iran in 2013. The sample size was determined based on the number of the constructs of the Trans-theoretical Model. Therefore, 50 samples selected for each construct, and 7\% was added (Hajizadeh \& Asghari, 2011). Sampling was performed through the multi-stage cluster sampling. The city was divided into four areas of north, south, east, and west. Then, one health care center was chosen randomly from each area, and the samples were selected randomly from the individuals admitted to the health care centers considering the inclusion criteria of the study. The inclusion criteria of the study were as follows: females aged 30-50 years old with educational level at least grade five of primary school, lack of rheumatoid disease and mental disorder, lack of fractures, pregnancy, menopause and breast-feeding, and consent to participate in the study. Before entering the study, the participants were provided with the necessary information about the study, and those who showed their willingness to participate through verbal informed consent were included in the study. The study was approved by the ethics boards of Tarbiat Modares University and Lorestan University of Medical Sciences. To collect the demographic information, a questionnaire of demographic information was applied, which included age, educational level, marital status, number of children, housework, menstrual age and abnormality, income, height and weight, and tea as well as supplements consumption.

The stage of change in physical activity was measured using the Stages of Exercise Change Questionnaire (SECQ) a 5-item questionnaire, prepared by Marcus et al (Marcus BH et al., 1992). The questionnaire was applied after its content validity index $(>0.7)$, content validity ratio $(0.59)$, and face validity $(\mathrm{IF}=5)$ were approved. The questionnaire put individuals in the stages of pre-contemplation (not thinking about behavioral change in osteoporosis prevention in the next 6 months), contemplation (thinking about behavioral change in osteoporosis prevention in the next 6 months), preparation (thinking about behavioral change in osteoporosis prevention in the next month), action (taking action to change in osteoporosis prevention in the previous day to 6 months), and maintenance (sustaining action in osteoporosis prevention for more than 6 months) (Sharma \& Romans, 2008). Since the questionnaire was dynamic in nature, it had one question at five levels. Therefore, the common methods for determining reliability were not appropriate for the questionnaire (Araban et al., 2013). 
However, since the process of validity confirmation was performed carefully, we can say that the questionnaire had the necessary reliability and validity. The questionnaire placed the individuals in one of the five stages. Therefore, a score of 1 to 5 was assigned to each stage. The preventive behavior in this study was defined as physical activity at least 5 days per week and for 30 minutes each time.

The questionnaire by Nigg et al. (1998) was applied to determine decisional balance (pros and cons), and Schowarzer and Renner's 5-point Health-specific Self-efficacy Scale to measure individuals' confidence in overcoming the current cons in performing regular physical activity. It should be noted that in this study one question was added by the researchers to the self-efficacy scale, and the decisional balance (pros and cons) scale included 11 questions for each variable equally (Karimzadeh Shirazi et al., 2007). Each question was scored based on a 5-point Likert scale ranging from 1 (extremely important) to 5 (completely unimportant). The total scores of the questionnaire for the constructs of pros and cons in decisional balance did not range from 11 to 55 . The content validity for the pros $(\mathrm{CVI}=0.99, \mathrm{CVR}=0.8)$, the content validity for the cons $(\mathrm{CVI}=0.88, \mathrm{CVR}=0.70)$, and the face validity $(\mathrm{IF}=1.5)$ were approved. The reliability of these two questionnaires was approved with a Cronbach's alpha of 0.88 . The self-efficacy questionnaire included six questions and was prepared based on the theory of Bandura's self-efficacy. The content validity $(\mathrm{CVI}=0.94, \mathrm{CVR}=0.71)$, the face validity $(\mathrm{IF}=1.5)$, and the reliability of the questionnaire (Cronbach's alpha $=0.82$ ) were approved. The answers of this tool were on a Likert scale ("I'm completely sure" to "I'm not sure") with a range of 6 to 24 scores.

The tool for assessing physical activity was the International Physical Activity Questionnaire (IPAQ). This tool records information on the amount of time spent by a person to walk (as exercise) and to do moderate or high physical activity in the past seven days. The tool was prepared by a group of international experts in 1998 in Geneva, and has already been so far applied in numerous studies, and its reliability and validity have been reported (Craig et al., 2003). The data were collected from the samples in one step and were analyzed with SPSS 16 using descriptive and inferential statistics (Chi-square test, Spearman and Mann-Whitney correlation coefficients). Logistic regression was performed to evaluate the predictive power of the model constructs in adopting the behaviors of osteoporosis prevention, so that the individuals in the stages of "pre-contemplation", "contemplation" and "preparation" were put into the "non-action" group (those without healthy behaviors), and those in the "action" and "maintenance" stages were included in the "action" group (those with healthy behaviors). The data were analyzed considering the significance level of 0.05 .

\section{Results}

The results showed the highest frequency (41\%) for the age group of 30-35, the lowest (17.8\%) for the age group of $45-50$, and the mean age of $38.72 \pm 7.003$. Moreover, $36.8 \%$ had high school diplomas, and $26 \%$ had academic degrees. With respect to marital status, $75.1 \%$ of the subjects were married. Regarding occupation, $75.1 \%$ were housewives, the rest were employed, and $73.1 \%$ of the subjects were working in state organizations. Concerning income, low income (less than 500,000 Tomans monthly $=170$ USD) with $46.5 \%$ and good income (more than 900,000 Tomans monthly $=300$ USD) with $20.4 \%$ had the highest and lowest frequencies respectively. The mean age of menarche was $13.84 \pm 1.9$, with the lowest menarche age of $9(0.4 \%)$ and the highest of 21 . In addition, the highest frequencies were found for the age of $14(33.1 \%)$ and $13(21.2 \%)$. Also, $11 \%$ of the subjects had experienced 1-5 miscarriages. Concerning number of children, $29.4 \%$ had two children. In terms of physical activity and housework, $7.8 \%$ of the subjects did not do housework, $33.8 \%$ did housework for 3 other individuals, and $22.7 \%$ for 4 other people. The results also showed that $76.6 \%$ of the women had no menstrual abnormalities, and only $23.4 \%$ had menstrual abnormalities out of whom $59(21.9 \%)$ had the abnormality of irregularity. The mean and standard deviation of weekly light physical activity was $38.83 \pm 56.400$ minutes, and the mean and standard deviation of moderate weekly physical activity was $4.77 \pm 29.119$ minutes (Table 1 ).

Table 1. Demographic Information of Women 30-50 age

\begin{tabular}{lll}
\hline & Variables & Percentage \\
\hline Age group & $30-35$ & 41 \\
Marital status & married & $75 / 1$ \\
Occupation & housewives & $75 / 1$ \\
Income status & $170 \mathrm{USD}$ & $46 / 5$ \\
& $300 \mathrm{USD}$ & $20 / 4$ \\
\hline
\end{tabular}




\begin{tabular}{lll}
\hline Menarche age $(y)$ & $<9$ & $0 / 4$ \\
& 13 & $21 / 2$ \\
& 14 & $33 / 1$ \\
Number of children & 2 & $29 / 4$ \\
\hline
\end{tabular}

The results of the construct of "stages of change" related to physical activity in the women showed that $43.5 \%$ of the women were in the pre-contemplation stage, and $9.4 \%$ in the maintenance stage in performing regular physical activity, as shown in Table 1. Also, in terms of the ranking of stages of change in physical activity, $82.9 \%$ were in the non-action phase and $17.1 \%$ in the action phase (Table 2). Table 3 shows the results of the constructs of stages of change related to physical activity in the women. Logistic regression was applied to determine the predictors of physical activity behavior (Table 4).

Results of the Mann-Whitney test showed a significant relationship between the constructs of stages of change and income $(\mathrm{p}<0.006)$. Also, the findings of Pearson test showed a statistically significant relationship between the constructs of stages of change with educational level $(\mathrm{p}<0.043)$, and occupation $(\mathrm{p}<0.014)$.

Table 2. Frequency distribution of the stages of change related to the variable of physical activity in the studied women based on action and non-action

\begin{tabular}{lll}
\hline \multirow{2}{*}{$\begin{array}{l}\text { Ranking of the stages of } \\
\text { change }\end{array}$} & \multicolumn{2}{l}{ Physical Activity } \\
\cline { 2 - 3 } & Frequency & Percentage \\
\hline Non-action & 223 & 82.9 \\
Action & 46 & 17.1 \\
\hline
\end{tabular}

Table 3: Frequency distribution of the stages of change related to the variable of physical activity in the studied women

\begin{tabular}{lll}
\hline \multirow{2}{*}{ Stages of change } & \multicolumn{2}{l}{ Physical Activity } \\
\cline { 2 - 3 } & Frequency & Percentage \\
\hline Pre-contemplation & 117 & 43.5 \\
Contemplation & 50 & 18.6 \\
Preparation & 56 & 20.8 \\
Action & 20 & 7.4 \\
Maintenance & 26 & 9.4 \\
\hline
\end{tabular}

Table 4: Predictive variables of stages of change related to physical activity behavior based on the Trans-theoretical model constructs

\begin{tabular}{lllll}
\hline \multirow{2}{*}{ Variable } & \multicolumn{2}{l}{ Confidence interval } & Odds ratio & P-value \\
\cline { 2 - 4 } & Upper & Lower & & 0.347 \\
\hline Income & 1.000 & 1.000 & 1.409 & 0.071 \\
Educational level & 2.046 & 0.971 & 1.170 & 0.000 \\
Self-efficacy of physical activity & 1.264 & 1.083 & 1.046 & 0.123 \\
Pros of physical activity & 1.025 & 0.933 & 0.978 & 0.358 \\
Cons of physical Coactivity & 1.109 & 0.988 & 1.384 & 0.490 \\
Occupation & 3.482 & 0.55 & & \\
\hline
\end{tabular}

\section{Discussion}

The findings showed that only the construct of "self-efficacy" among the applied constructs of the Trans-theoretical Model had the predictive power for the behavior. The results of a comprehensive study by 
Schwarzer et al. indicated that self-efficacy could have a higher predictive power in health behaviors than the other constructs (Schwarzer \& Fuchs, 1996). The results of Berry et al. and Kim's studies on exercise behavior, Swaim's study on the relationship between physical activity self-efficacy and physical activity behavior, and Dishman's et al study reported self-efficacy as the most important predictor of the behavior (Kim, 2004; Berry et al., 2005; Swaim et al., 2008; Gammage et al., 2009; Dishman et al, 2010; Khave et al, 2014). It seems that adopting preventive behaviors for osteoporosis is also more dependent on self-efficacy. Bandura, as the developer of the theory of self-efficacy, believes that self-efficacy is specific to a specific behavior. An individual may have high self-efficacy in one behavior and low self-efficacy in another one (Sharma \& Romans, 2008; Bandura, 1977; Kim, 2004; Berry et al., 2005; Swaim et al., 2008; Gammage et al., 2009). Bandura a mentions four factors of success in performance, succession experiences, verbal encouragement, and physiological and emotional arousal as the sources of self-efficacy (Bandura, 2006). Therefore, self-efficacy is an important component of success, which falls in the field of positive psychology (Snyder \& Lopez, 2002). The construct of self-efficacy, or belief in "I can", refers to a person's ability to perform tasks in certain circumstances. Additionally, another type of self-efficacy refers to the person's overall belief about his or her own abilities and capabilities (Mazloumi Mahmoud Abad et al., 2010).

Based on the results of our study, $79.9 \%$ of the women were in the no-action stage (pre-contemplation, contemplation, and preparation), and $20.1 \%$ were in the action stage (action and maintenance) through adopting regular physical activity. Also, most of the women $(41.3 \%)$ were in the pre-contemplation stage and the lowest number $(6.7 \%)$ in the action stage, while in Nigg et al.'s study most of the subjects $(49.3 \%)$ were in the maintenance, the lowest number $(2.1 \%)$ in the pre-contemplation stage, and $3.8 \%$ in the action stage (Nigg \& Courneya, 1993). In Mazloumi et al.'s study (2010), 20\% of the subjects were in the pre-contemplation stage, $40 \%$ in the contemplation stage, $13.6 \%$ in the preparation stage, $7.3 \%$ in the action stage, and $19 \%$ in the maintenance stage (Mazloumi Mahmoud Abad et al., 2010). Therefore, regular physical activity according to regular and specific patterns should be part of an overall strategy to prevent osteoporosis in women, so that an individual can change behavior intentionally (DiClemente, 2005). The results of our study did not show significant differences in the scores of the constructs in terms of marital status. However, Tol et al.'s study indicated that self-efficacy was associated with marital status (Tol et al., 2012). This contrast might be justified according to cultural and social contexts of the studies. Married people spend most of their time on daily life activities, and therefore spend less time on regular physical activity because of the higher responsibilities they have in compares with the other members of their families. However, this interpretation is not always correct. Investigating the relationship between the constructs of the Trans-theoretical Model and regular physical activity revealed that the studied women used more cognitive and behavioral processes in order to adopt physical activity behavior and possessed higher self-efficacy in physical activity when they were in higher stages of change. Based on the Trans-theoretical Model, individuals can go through the stages of change by gaining experience and skills. Returning to the previous stages may even happen, which is justifiable considering the circular nature of the model. The results of our study on decisional balance showed that the central components of pros and cons in this construct are crucial in making decisions on physical activity. The results showed that the individuals in the pre-contemplation stage had negative comments on physical activity such as being time-consuming and tedious (cons), while the women in the maintenance stage had positive comments on physical activity (pros) (Omar-Fauzee et al., 2009; Moeini et al., 2011).

The results showed no significant relationship between the construct of decisional balance and physical activity. This result is consistent with the results of Moeini et al. and Araban et al.'s studies, but inconsistent with the studies conducted by Kidd et al. and Omar-Fauzee et al (Omar-Fauzee et al., 2009; Kidd \& Peters, 2010; Moeini et al., 2011; Araban et al., 2013). Therefore, these results suggest that the construct did not have the power to predict the behavior of physical activity. This predictive inability of the pros and cons constructs can be attributed to the high points of these two constructs in the studied population in our study. Therefore, as it is emphasized by Pawlak et al. (Pawlak \& Colby, 2009), high scores of pros and low scores of cons cannot predict health behaviors. It is also possible that adopting preventive behaviors (physical activity) for osteoporosis is more dependent on self-efficacy.

The results of the present study showed that, among the constructs the Trans-theoretical Model, self-efficacy is the only construct that can predict the adoption of osteoporosis prevention behavior. Therefore, it is recommended to conduct more extensive studies to confirm our finding. The study did not use the construct of processes of change due to the probable numerous items in the questionnaire in two behaviors of physical activity and calcium intake, and answering the questions took a long time, and these were the limitations of the study. This study is among the first studies carried out on behavior change to prevent osteoporosis in women 
aged 30-50 in Khorramabad based on the patterns of health education and enhancement.

\section{Acknowledgements}

We hereby appreciate the sincere help of all the subjects of the study for giving their precious time to us, Dr. Ghofranipour for providing valuable guidance, and the Medical Research Council of Tarbiat Modarres University for approving the study. This study is a part of a doctoral thesis on health education and promotion in the faculty of medicine at Tarbiat Modarres University.

\section{References}

Adib, M. G., \& Nauroy, L. (2011). The Middle East \& Africa Regional Audit, Epidemiology, costs \& burden of Osteoporosis in 2011. Retrieved from www.iofbonehealth.org; 22-25.

Alev, A., \& Merih, Y. (2003). Evaluation of Hormonal Responses and Ulterasonic Changes in the Heel Bone by Aquatic Exercise in Sedentary Postmenopausal Women. American Journal of Physical Medicine and Rehabilitation, 82, 942-949. http://dx.doi.org/10.1097/01.PHM.0000098039.58584.59

Araban, M., Tavafian, S. S., Mitesaddi Zarandi, S., Haidarnia, A. R., Gohari, M. R., Laloli, A., \& Montazeri, A. (2013). Prediction of Air Pollution Exposure Behavior among Pregnant Women: A Trans-theoretical Model -Based Study. Journal of Knowledge \& Health, 8, 83-88. [In Persian]

Bandura, A. (1977). Self-efficacy: toward a unifying theory of behavioral change. Psychological review, 84, 191-215. http://dx.doi.org/10.1037/0033-295X.84.2.191

Bandura, A. (1982). Self-efficacy mechanism in human agency. American Psychologist, 37, 122-127. http://dx.doi.org/10.1037/0003-066X.37.2.122

Bandura, A. (1977). Self-efficacy: toward a unifying theory of behavioral change. Psychological review, 84, 19. http://dx.doi.org/10.1037/0033-295X.84.2.191

Bandura, A. (2006). Guide for constructing self-efficacy scales. Self-efficacy beliefs of adolescents, 5, 307-337.

Berry, T., Naylor, P. J., \& Wharf-Higgins, J. (2005). Stages of change in adolescents: an examination of self-efficacy, decisional balance and reasons for relapse. Journal of adolescent health, 37, 452-459. http://dx.doi.org/10.1016/j.jadohealth.2004.09.019

Blume, S. W., \& Curtis, J. R. (2011). Medical costs of osteoporosis in the elderly Medicare population. Osteoporosis International, 122, 1835-1844. http://dx.doi.org/10.1007/s00198-010-1419-7

Butler, J. T. (2001). Principles of health education and health promotion: Wads Worth.

Chan, M. F., Kwong, W. S., Zang, Y. L., \& Wan, P. Y. (2007). Evaluation of an osteoporosis prevention education program for young adults. Journal of advanced nursing, 57, 270-285. http://dx.doi.org/10.1111/j.1365-2648.2006.04091.x

Craig, C. L., Marshall, A. L., Sjostrom, M., Bauman, A. E., Booth, M. L., Ainsworth, B. E., ... Oja, P. (2003). International Physical Activity Questionnaire: 12-Country Reliability and Validity. Medical and science in sports and Exercise, 35, 1381-1395. http://dx.doi.org/10.1249/01.MSS.0000078924.61453.FB

De Vet, E., de Nooijer, J., de Vries, N. K., \& Brug, J. (2007). Comparing stage of Change and behavioral intention to understand fruit intake. Health Education Research, 22, 599-608. http://dx.doi.org/10.1093/her/cyl121

De Vet, E., de Nooijer, J., de Vries, N. K., \& Brug, J. (2008). Testing the transtheoretical model for fruit intake: comparing web-based tailored stage-matched and stage-mismatched feedback. Health Education Research, 23, 218-227. http://dx.doi.org/10.1093/her/cym019

Department of the Women's Sport (DWS), (Ed.) (2005). Woman and sport (p. 97). Tehran: Publication of the Research and Education Office. [In Persian]

Di Clemente, C. C. (2005). Conceptual models and applied research: the ongoing contribution of the $\begin{array}{lllll}\text { transtheoretical model. Journal of Addictions Nursing, } & 16, & \text { 5-12. }\end{array}$ http://dx.doi.org/10.1080/10884600590917147

Dishman, R. K., Vandenberg, R. J., Robert, W., Motl, R. W., \& Nigg, C. R. (2010). Using Constructs of the Transtheoretical Model to Predict Classes of Change in Regular Physical Activity: A Multi-Ethnicm Longitudinal Cohort Study. Ann Behav Med, 40, 150-163. http://dx.doi.org/10.1007/s12160-010-9196-2

Ebrahim, Kh., Ramezanpoor, M., \& Rezaee, A. (2010). Effect of Eight of Aerobic and Progressive Exercises on 
Change of Estrogen Hormone and Effective Factors on Bone Mass in Menopause Sedentary Women. Iranian Journal of Endocrinology and Metabolism, 12, 401-408. [In Persian]

Gammage, K. L., Francoeur, C., Mack, D.E., \& Klentrou, P. (2009). Osteoporosis health beliefs and knowledge in college students: The role of dietary restraint. Eating behaviors, 10, 65-67. http://dx.doi.org/10.1016/j.eatbeh.2008.10.006

Glanz, K., Rimer, B. K., \& Viswanath, K. (2008). Health Behavior and Health Education: Theory, Research, and Practice (4th ed.), Jossey-Bass: San Francisco, 2008.

Habibzadeh, S. N., Rahmani-Nia, F., \& Daneshmandi, H. (2009). The Effect of Selected Walking Program on Bone Mass Density, Body Composition and Serum Estrogen in OBESE Girls. Knowledge \& Health, 4, 8-12. [In Persian]

Hajizadeh, E., \& Asghari, M. (2011). Statistical Methods and Analyses in Health and Biosciences, A Research Methodological Approach. Tehran: Jahad Daneshghahi, 5, 395-422. [In Persian]

Hazavehei, S. M., Taghdisi, M. H., \& Saidi, M. (2007). Application of the Health Belief Model for osteoporosis prevention among middle school girl students, Garmsar, Iran. Educ Health. (Abingdom), 20, 23-24. [In Persian]

Heaneyh, P. R., \& Weaver, C. M. (2003). Calcium and Vitamin D. Endocrinology and Metabolism Clinics of North America, 32, 181-194. http://dx.doi.org/10.1016/S0889-8529(02)00063-4

Karimzadeh Shirazi, K. M., Wallace, L., Niknami, S., Hidarnia, A. R, Torkaman. G., Mollie Gilchrist, M., \& Soghrate Faghihzadeh, S. (2007). A home-based, transtheoretical change model designed strength training intervention to increase exercise to prevent osteoporosis in Iranian women aged 40-65 years: a randomized controlled trial. Journal of Health Education Research, 22, 305-317. [In Persian] http://dx.doi.org/10.1093/her/cyl067

Kave, M. H., Golij, M., Nazari, M., Mazloom, Z., \& Rezaeian Zadeh, A. (2014). Effects of an osteoporosis prevention training program on physical activity-related stages of change and self-efficacy among university students, Shiraz, Iran: a Randomized clinical Trial. J. Adv. Med. Edu. Prof, 2, 158-164.

Khawaji, M. H., Astermark, K., Akesson, E., \& Berntorp, A. (2010). Physical activity for prevention of osteoporosis in patients with severe haemophilia on long -term prophylaxis. Hemophilia, 16, 495-501. http://dx.doi.org/10.1111/j.1365-2516.2009.02186.x

Khorsandi, M., Shamsi, M., \& Jahani, F. (2011). Effect of education based on Health Belief Model on osteoporosis preventive behaviors among pregnant women referred to Arak health centers. Journal of Shahed University Research-Science, 18, 23-27. [In Persian]

Kidd, T., \& Peters, P. K. (2010). Decisional balance for health and weight is associated with whole-fruit intake in low-income young adults. Nutrition Research, 30, 477-482. http://dx.doi.org/10.1016/j.nutres.2010.07.003

Kim, Y. (2004). Korean adolescents' exercise behavior and its relationship with psychological variables based on stages of change model. Journal of adolescent health, 34, 523-530. http://dx.doi.org/10.1016/S1054-139X(03)00349-5

Lawrence, T., Aveyard, P., Cheng, K., Griffin, C., Johnson, C., \& Croghan, E. (2005). Does stage-based smoking cessation advice in pregnancy result in long-term quitters? 18-month postpartum follow-up of a randomized controlled trial. Addiction, 100, 107-116. http://dx.doi.org/10.1111/j.1360-0443.2005.00936.x

Lee, Y. M. (2004). Process of change, decisional balance and self-efficacy corresponding to stage of change in exercise behaviors in middle women. Sport Med. Phys. Fitness, 34, 362-371.

Lowe, N. M., Basma, N., Ellahi Qudsia, B., Sonia Bangash, A., Soma, R., Mitra, \& Zaman, M. (2011). Dietary Calcium Intake, Vitamin D Status, and Bone Health in Postmenopausal Women in Rural Pakistan. Health Popular Nutrition, 29, 465-470.

Maimoun, L., Simar, D., Malatesta, D., Caillaud, C., Peruchon, E., Couret, I., Rossi, M., \& Mariano-Goulart, D. (2005). Response of bone metabolism related hormones to a single session of strenuous exercise in active elderly subjects. British journal of sports medicine, 39, 497-502. http://dx.doi.org/10.1136/bjsm.2004.013151

Marcus, B. H., Rossi, J, S., Selby, V. C., Niaura, R. S., \& Abrams, D. B. (1992). The stages and processes of exercise adoption and maintenance in a worksite sample. Health Psychology, 11, 386-395. http://dx.doi.org/10.1037/0278-6133.11.6.386 
Mazloumi Mahmoud Abad, S. S., Mohammadi, M., \& Morovati Sharif Abad, M. A. (2010). Exercise and its relationship with self-efficacy based on the pattern of stages of change in employees in Yazd in 2008. Journal of Kerman University of Medical Sciences, 17, 35-46. [In Persian]

Moayyeri, A., Soltani, A., Larijani, B., Naghavi, M., Alaeddini, F., \& Abolhassani, F. (2006). Epidemiology of hip fracture in Iran: Results from the Iranian multicenter study on accidental injuries. Osteoporosis International, 17, 1252-1557. http://dx.doi.org/10.1007/s00198-006-0105-2

Moeini, B., Hezavehie, S. M. M., Jalilian, M., Moghim, Beigi, A., \& Tarighseresht, N. (2011). Effective factors on physical activity and metabolic control in type-2 diabetic women admitted to the Diabetes Research Center of Hamedan based on the Trans-theoretical Model. Scientific Journal of Hamedan University ofMedical Sciences, 18, 31-37. [In Persian]

Nigg, C. R., \& Courneya, K. S. (1993). The stage of exercise behavior. The Journal of sports medicine and physical fitness, 33, 83-88.

Nigg, C. R., Rossi, J. S., Norman, G. J., \& Benisovich, S. V. (1998). Structure of decisional balance for exercise adoption. Annals of Behavioral Medicine, 20, S211.

Omar-Fauzee, M. S., Lian, T. S., Ha Loon, A., Nazaruddin, M. N., \& Abd Rashid, S. (2009). Application of Transtheoretical Theory Model to Understand the Physical Activity Behavior Among Women in Klang Valley Malaysia. European Journal of Social Sciences, 9, 88-97.

Parker, E., Baldwin, G., Israel, B., \& Salinas, M. (2004). Application of health promotion theories and models for environmental health. Health Education \& Behavior, 31, 491-509. http://dx.doi.org/10.1177/1090198104265601

Pawlak, R., \& Colby, S. (2009). Benefits, barriers, self-efficacy and knowledge regarding healthy foods; Perception of African Americans living in eastern North Carolina. Nutrition Research and Practice, 3, 56-63. http://dx.doi.org/10.4162/nrp.2009.3.1.56

Prevention disease office (PDO), (2009). Ministry of health and medical education. Guide to diagnosis, prevention and treatment of osteoporosis. Tehran: Public Centered prevention disease, 2009.

Prochaska, J. O., \& Marcus, B. H. (1994). The transtheoretical model: applications to exercise. In Dishman, R. K. (ed.), Advances in Exercise Adherence. Human Kinetics, Champaign, IL.

Prochaska, J. O., Reddind, C. A., \& Ever, K. E. (2008). The Transtheoretical Model and stage of change. In K. Glanz, B. K. Rimer, \& F. M. Lewis (Eds.), Health Behavior and Health Education, Theory, Research and Practice (4th ed., 40, 97-121), San Francisco: Jossey-Bass.

Prochaska, J. O., \& Velicer W. F. (1997). The Transtheoretical Model of the health behavior change. Am. J. Health Prom., 12, 38-48. http://dx.doi.org/10.4278/0890-1171-12.1.38

Prochaska, J. O., \& DiClement, C. C. (1983). Stages and processes of selfchange of smoking toward: An integrative model of change. $J$ Consult Clin Psychol., 4, 390-395. http://dx.doi.org/10.1037/0022-006X.51.3.390

Prochaska, J. O., DiClemente, C. C., \& Norcross, J. C. (1992). In search of how people change: Applications to addictive behaviors. American Psychologist, 47, 1102-1114. http://dx.doi.org/10.1037/0003-066X.47.9.1102

Rollnick, S., Miller, W. R., \& Butler, C. (2007). Motivational interviewing in health care: helping patients change behavior (1st ed.). New York: The Guilford Press.

Salehi, I., Khazaeli, S., Najafizadeh, S.R., Ashraf, H., \& Malekpour, M. (2009). High prevalence of low bone density in young Iranian healthy individuals. Clinical Rheumatology, 28, 173-177. http://dx.doi.org/10.1007/s10067-008-1008-8

Salehi, L., Eftekhar, H., Mohammad, K., Taghdisi, M. H., \& Shojaeizadeh, D. (2010). Physical activity among a sample of Iranians aged over 60 years: An application of the trans-theoretical model. Archive of Iran Medicine, 13, 528-536. [In Persian]

Schüz, B., Sniehotta, F. F., Mallach, N., Wiedemann, A. U., \& Schwarzer, R. (2009). Predicting transitions from preintentional, intentional and actional stages of change. Health Education Research, 24, 64-75. http://dx.doi.org/10.1093/her/cym092

Schwarzer, R., \& Fuchs, R. (1996). Self-efficacy and health behaviors. Predicting health behavior, 163-96. Retrieved from http://userpage.fu berlin.de / gesund /publicat/conner9.htm 
Schwellnus, M. P., Patel, D. N., Nossel, C., Dreyer, M., Whitesman, S., Micklesfield, L., \& Derman, E. W. (2011). Healthy lifestyle interventions in general practice part 13: lifestyle and osteoporosis: CPD article Journal of South African Family Practice, 53, 31-39.

Sharma, M., \& Romans, J. A. (2008). Theoretical Foundations of Health Education and Health Promotion (P. 91). Sudbury, USA: Jones and Bartlett.

Sharma, S. V., Hoelscher, D. M., Kelder, S. H., Diamond, P., Day, R. S., \& Hergenroeder, A. (2010). Psychosocial factors influencing calcium intake and bone quality in middle school girls. Journal of the American Dietetic Association, 110, 932-936. http://dx.doi.org/10.1016/j.jada.2010.03.013

Snyder, C. R., \& Lopez, S. J. (2002). Handbook of positive psychology. New Yourk: Oxford University press, 3-9.

Swain, R. A., Barner, J. C., \& Brown, C. M. (2008). The relationship of calcium intake and exercise to osteoporosis health beliefs in postmenopausal women. Research in Social and Administrative Pharmacy, 4, 153-163. http://dx.doi.org/10.1016/j.sapharm.2007.03.004

Tol, A., Esmaeili, S., Alhani, F., Mohajeri Tehrani, M., \& Shojaeizadeh, D. (2012). Self-efficacy: An efficient functional concept in type 2 diabetes control. Health System Research, 8, 1-9. [In Persian]

Tussing, L., \& Chapman- Novakofski, K. (2005). Osteoporosis prevention Education: Behavior Theories and calcium Intake. Journal of the American Dietetic Association, 105, 92-97. http://dx.doi.org/10.1016/j.jada.2004.10.025

Velicer, W. F., Prochaska, J. D., Rossi, J. S., \& Snow, M. (2001). Assessing outcome in smoking cessation studies. Psychol Bull., 11, 23-41.

YalçInkaya-Alkar, O., \& Karanci, A. N. (2007). What are the differences in decisional balance and self-efficacy between Turkish smokers in different stages of change? Addictive Behaviors, 32, 836-849. http://dx.doi.org/10.1016/j.addbeh.2006.06.023

Yasin, S. M., Taib, K. M., \& Zaki, R. A. (2011). Reliability and construct validity of the Bahasa Malaysia version of transtheoretical model (TTM) questionnaire for smoking cessation and relapse among Malaysian adult. Asian Pac J Cancer Prev., 212, 1439-1443.

\section{Copyrights}

Copyright for this article is retained by the author(s), with first publication rights granted to the journal.

This is an open-access article distributed under the terms and conditions of the Creative Commons Attribution license (http://creativecommons.org/licenses/by/3.0/). 